\title{
Mathematical modeling of shallow-water flows on steep slopes
}

\author{
Yufang $\mathrm{Ni}^{1 *}$, Zhixian $\mathrm{Cao}^{1}$, Qingquan $\mathrm{Liu}^{2}$ \\ ${ }^{1}$ State Key Laboratory of Water Resources and Hydropower Engineering Science, Wuhan University, Wuhan 430072, China. \\ 2 Department of Mechanics, Beijing Institute of Technology, Beijing 100081, China. \\ * Corresponding author. Tel.: +86 131-6329-2052. E-mail: yufangni@whu.edu.cn
}

\begin{abstract}
A 2D hydrodynamic (labeled as CAR) model has been proposed in a rectangular Cartesian coordinate system with two axes within the horizontal plane and one axis along the vertical direction (global coordinates), considering the effects of bed slope on both pressure distribution and bed shear stresses. The CAR model satisfactorily reproduces the analytical solutions of dam-break flow over a steep slope, while the traditional Saint-Venant Equations (labeled as SVE) significantly overestimate the flow velocity. For flood events with long duration and large mean slope, the CAR and the SVE models present distinguishable discrepancies. Therefore, the proposed CAR model is recommended for applications to real floods for its facility of extending from 1D to 2D version and ability to model shallow-water flows on steep slopes.
\end{abstract}

Keywords: 2D shallow-water equations; Steep slopes; Dam-break flows; Rectangular Cartesian coordinate system; Global coordinates.

\section{INTRODUCTION}

Shallow-water hydrodynamic models and their extensions involving sediment transport have been widely used in hydraulic engineering and geomorphological studies over the past few decades (Cao et al., 2017; Huang et al., 2014; Li et al., 2017, 2018a, 2018b; Qian et al., 2015). The prototype is the traditional Saint-Venant equations (Barré de Saint-Venant, 1871), which can be obtained by assuming a vertical hydrostatic pressure distribution and integrating three-dimensional Reynoldsaveraged Navier-Stokes equations over the flow depth (Toro, 2001; Wu, 2007). Yet the assumption of small slope is invalid for cases with realistic steep terrain (Denlinger and O'Connell, 2008; Juez et al., 2017).

The governing equations of granular flows described by the continuum theory bear a superficial resemblance to the shallowwater equations (Mangeney-Castelnau et al., 2005). Since the granular flows often take place on steep slopes, it is inevitable to incorporate the steep slope effects in the mathematical models. Savage and Hutter (1989) introduced the presence of steep slope by adopting local coordinates with one axis along the bed and the other axis perpendicular to the bed. Then Savage and Hutter (1991) derived 1D governing equations in a curvilinear coordinate system (local coordinates) aligned with the curved bed, which were later extended by Greve et al. (1994) to study 3D granular flows along a bottom profile that was weakly curved downward and plane laterally. Gray et al. (1999) modeled the realistic complex basal topography by defining an orthogonal curvilinear reference surface and then superposing shallow basal topography on it. Since the topographic data for natural spaces is mainly based on digital elevation models (DEMs), which are referenced to global coordinates, the aforementioned models have to map the original data to local coordinates. In this connection, Denlinger and Iverson (2004) developed a nonhydrostatic model in global coordinates, accounting for the effects of nonzero vertical accelerations. Juez et al. (2013) simulated granular flows using both global and local coordinates, assuming hydrostatic pressure distribution normal to the bed. Castro-Orgaz et al. (2015) further modified the nonhydrostatic model, including the effects of vertical motion without the ad hoc assumptions adopted by Denlinger and Iverson (2004).

As for shallow-water flows, Bouchut et al. (2003) and Keller (2003) introduced a new 1D shallow-water model in a curvilinear coordinate system aligned with the bottom topography, which relaxed the restriction of small slopes of the SaintVenant equations and was valid for arbitrary slopes. Ancey et al. (2008), Cao et al. (2015) and Fernandez-Feria (2006) applied the modified version of the Saint-Venant equations in local coordinates to model shallow water flows on uniform slopes. As establishing models in global coordinates can simplify the mathematical expressions of governing equations and the process of data handling, Denlinger and O'Connell (2008) followed the nonhydrostatic model proposed by Denlinger and Iverson (2004), which was then further developed by CanteroChinchilla et al. (2017) and Castro-Orgaz and Hager (2017). On the other hand, Juez et al. (2017), Van Emelen (2014) and Van Emelen et al. (2014) built hydrodynamic models in global coordinates following Juez et al. (2013). Van Emelen (2014) and Van Emelen et al. (2014) concluded that for rapid flows such as dam-break flows, no difference appears between traditional and modified models; however, differences are detectable for uniform flows on slope with bed angles higher than $10^{\circ}$. Juez et al. (2017) investigated the influence of gravity effects on bed load transport over steep slopes.

In the present work, a shallow-water hydrodynamic model is established in global coordinates, based on the assumption of hydrostatic pressure distribution normal to the bed. In addition, the bed slope is incorporated in the calculation of bed shear stresses. This paper aims to shed new insights on the bed slope effects by comparing the performance of the traditional SaintVenant equations and the proposed model in applications to four dam-break flood events.

\section{MATHEMATICAL MODEL Governing equations}

The effects of bed slope on both pressure distribution and bed shear stresses are considered in the governing equations here, which is different from the traditional Saint-Venant equa- 


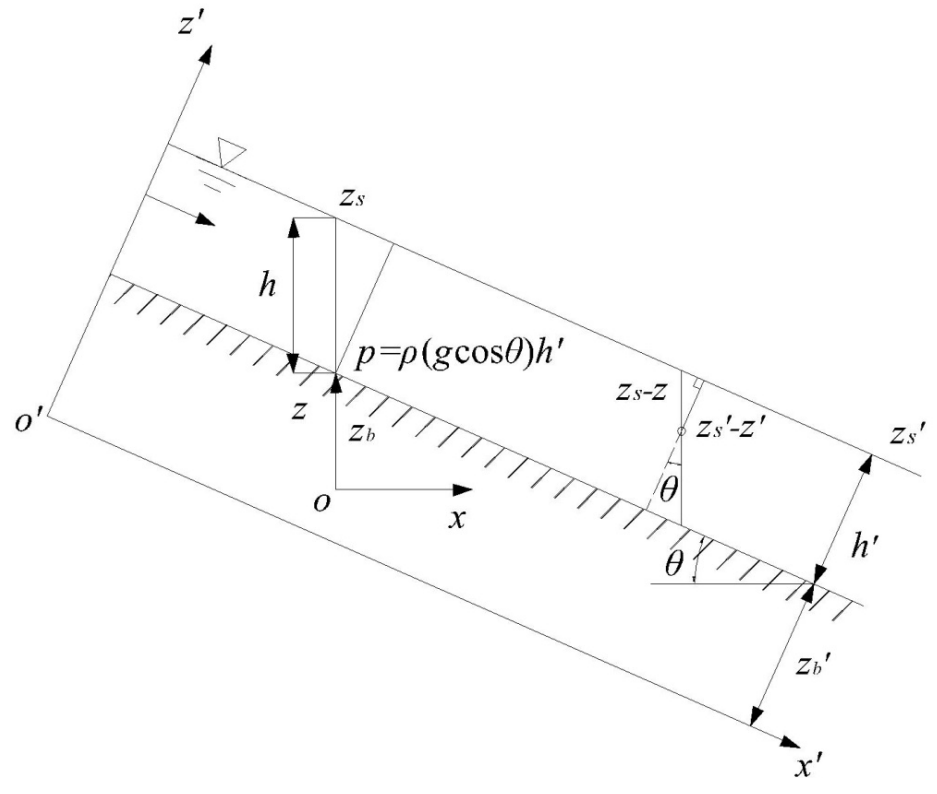

Fig. 1. Sketch for local and global coordinates.

tions valid for small slopes. Figure 1 illustrates the comparison of local and global coordinates. In local coordinates $\left(x^{\prime} o^{\prime} z^{\prime}\right)$, the pressure distribution normal to the bed is

$$
p=\rho g \cos \theta \cdot\left(z_{s}{ }^{\prime}-z^{\prime}\right)
$$

where $\rho$ is the density of water; $g$ is gravitational acceleration; $\theta$ is the slope angle of the bed; $z_{s}{ }^{\prime}$ is the free surface in local coordinates. According to geometric relation, the vertical pressure distribution in global coordinates $(x o z)$ is

$$
p=\rho g \cdot \cos ^{2} \theta \cdot\left(z_{s}-z\right)
$$

Note that in the traditional Saint-Venant equations (with the assumption of small slopes so there is $\cos \theta \approx 1)$, the vertical pressure distribution in global coordinates $(x o z)$ is

$$
p=\rho g \cdot\left(z_{s}-z\right)
$$

Substitutions of Equations (1)-(3) into time-averaged 3D momentum equations of incompressible flow in corresponding Cartesian coordinate systems, together with integrations along flow depth, yield three sets of depth-averaged equations, respectively ( $\mathrm{Wu}, 2007$ ).

The 1D governing equations derived with Equation (1) in local coordinates are given as follows

SWE: $\left\{\begin{array}{l}\frac{\partial h^{\prime}}{\partial t}+\frac{\partial\left(h^{\prime} u^{\prime}\right)}{\partial x^{\prime}}=0 \\ \frac{\partial\left(h^{\prime} u^{\prime}\right)}{\partial t}+\frac{\partial}{\partial x^{\prime}}\left(h^{\prime} u^{\prime 2}+\frac{1}{2} g \cos \theta \cdot h^{\prime 2}\right)= \\ g h^{\prime} \sin \theta-g \cos \theta \cdot h^{\prime} \frac{\partial z_{b}^{\prime}}{\partial x^{\prime}}-\frac{1}{\rho} \tau_{b}{ }^{\prime}\end{array}\right.$

where $t$ is time; $x^{\prime}$ is the downstream coordinate; $h^{\prime}$ is the flow depth perpendicular to the bed; $u^{\prime}$ is the depth-averaged stream-wise flow velocity; $z_{b}{ }^{\prime}$ is the bed elevation in local coordinates; $\tau_{b}{ }^{\prime}$ is the bed shear stress. This model is referred to as SWE (modified shallow water equations) in this paper. Since its $2 \mathrm{D}$ version is complex, only $1 \mathrm{D}$ version is presented here.
As for Equations (2) and (3), the corresponding governing equations are built in global coordinates and therefore the $2 \mathrm{D}$ versions can be readily derived

$$
\begin{aligned}
& \frac{\partial h}{\partial t}+\frac{\partial(h u)}{\partial x}+\frac{\partial(h v)}{\partial y}=0 \\
& \frac{\partial(h u)}{\partial t}+\frac{\partial\left(h u^{2}\right)}{\partial x}+\frac{\partial(h u v)}{\partial y}=-\frac{\partial}{\partial x}\left(\frac{1}{2} g^{\prime} h^{2}\right)-g^{\prime} h \frac{\partial z_{b}}{\partial x}-\frac{1}{\rho} \tau_{b x} \\
& \frac{\partial(h v)}{\partial t}+\frac{\partial(h u v)}{\partial x}+\frac{\partial\left(h v^{2}\right)}{\partial y}=-\frac{\partial}{\partial y}\left(\frac{1}{2} g^{\prime} h^{2}\right)-g^{\prime} h \frac{\partial z_{b}}{\partial y}-\frac{1}{\rho} \tau_{b y}
\end{aligned}
$$

where $x$ and $y$ are the horizontal Cartesian coordinates; $h$ is the vertical flow depth; $u$ and $v$ are the depth-averaged velocity components in the $x$ - and $y$ directions; $z_{b}$ is the vertical bed elevation; $\tau_{b x}$ and $\tau_{b y}$ are the bed shear stresses in the $x$ - and $y$-directions, respectively. According to Equation (2), there is

$g^{\prime}= \begin{cases}g \cdot \cos ^{2} \theta & \text { if } \sqrt{u^{2}+v^{2}}>0 \\ 0 & \text { else }\end{cases}$

The model with Equations (5) and (6) is referred to as the CAR (the first three letters of "Cartesian") model in this paper. On the other hand, the traditional SaintVenant equations with $g^{\prime}=g$ are labeled as the SVE (Saint-Venant Equations) model.

\section{Model closure}

To close the governing equations above, the Manning formula is employed here to evaluate the bed shear stresses

$$
\begin{aligned}
& \tau_{b x}=\rho \frac{n^{2} \cdot g}{(h \cos \theta)^{1 / 3}} \cdot \frac{u \sqrt{u^{2}+v^{2}}}{\cos \theta} \\
& \tau_{b y}=\rho \frac{n^{2} \cdot g}{(h \cos \theta)^{1 / 3}} \cdot \frac{v \sqrt{u^{2}+v^{2}}}{\cos \theta}
\end{aligned}
$$

where $n$ is the Manning roughness coefficient. As mentioned above, there is $\cos \theta \approx 1$ in the SVE model. For the SWE model, the angle-related terms would not be included in Equation (7) due to the consistency between the axis and the flow direction.

The cosine value of the bed angle of the computational grid $(i, j)$ in the CAR model is given by

$\cos \theta(i, j)=1 / \sqrt{1+\left(\frac{z_{b i+1, j}-z_{b i-1, j}}{2 \cdot \Delta x}\right)^{2}+\left(\frac{z_{b i, j+1}-z_{b i, j-1}}{2 \cdot \Delta y}\right)^{2}}$

where $\Delta x$ and $\Delta y$ are the spatial steps; the subscripts $i$ and $j$ denote the spatial node indexes in the $x$ - and $y$ directions, respectively. 


\section{Numerical algorithm}

Equation (5) constitutes a hyperbolic system which can be written in a quasi-linear form as

$$
\begin{aligned}
& \frac{\partial \mathbf{U}}{\partial t}+\frac{\partial \mathbf{F}}{\partial x}+\frac{\partial \mathbf{G}}{\partial y}=\mathbf{S} \\
& \mathbf{U}=\left[\begin{array}{l}
h \\
h u \\
h v
\end{array}\right] \\
& \mathbf{F}=\left[\begin{array}{c}
h u^{2}+0.5 g^{\prime} h^{2} \\
h u v
\end{array}\right] \\
& \mathbf{G}=\left[\begin{array}{c}
h v \\
h v^{2}+0.5 g^{\prime} h^{2}
\end{array}\right] \\
& \mathbf{S}=\mathbf{S}_{b}+\mathbf{S}_{f}=\left[\begin{array}{c}
0 \\
-g^{\prime} h \frac{\partial z_{b}}{\partial x} \\
-g^{\prime} h \frac{\partial z_{b}}{\partial y}
\end{array}\right]+\left[\begin{array}{c}
0 \\
-\frac{1}{\rho} \tau_{b x} \\
-\frac{1}{\rho} \tau_{b y}
\end{array}\right]
\end{aligned}
$$

where $\mathbf{U}$ is the vector of conserved variables; $\mathbf{F}$ and $\mathbf{U}$ are the convective flux vectors of the flow in the $x$ - and $y$ - directions, respectively; $\mathbf{S}_{b}$ is the source term related to the pressure force at the bed; $\mathbf{S}_{f}$ is the source term involving bed shear stresses. Under the framework of finite volume method, an explicit discretization of Equation (9) gives (Hou et al., 2013a, 2013b; Huang et al., 2015)

$$
\mathbf{U}_{i, j}^{*}=\mathbf{U}_{i, j}^{n}+\Delta t \cdot \mathbf{S}_{f i, j}^{n+1}
$$

$\mathbf{U}_{i, j}^{n+1}=$

$\mathbf{U}_{i, j}^{*}-\Delta t \cdot\left[\frac{\left(\mathbf{F}_{i+1 / 2, j}^{*}-\mathbf{F}_{i-1 / 2, j}^{*}\right)}{\Delta x}+\frac{\left(\mathbf{G}_{i, j+1 / 2}^{*}-\mathbf{G}_{i, j-1 / 2}^{*}\right)}{\Delta y}\right]+\Delta t \cdot \mathbf{S}_{b i, j}{ }^{*}$

where the superscript $n$ denotes the time step index; $\Delta t$ is the time step; $\mathbf{F}_{i+1 / 2, j}^{*}, \mathbf{F}_{i-1 / 2, j}^{*}, \mathbf{G}_{i, j+1 / 2}^{*}$, and $\mathbf{G}_{i, j-1 / 2}^{*}$ represent the inter-cell fluxes.

The friction source term in Equation (11) is evaluated by the splitting point-implicit method (Bussing and Murmant, 1988; Huang et al., 2015). The Monotone Upstream-centered Schemes for Conservation Laws (MUSCL) method is used in data reconstruction to achieve second-order accuracy in space and a second-order Runge-Kutta method is employed to solve Equation (12) to obtain second-order accuracy in time (Hou et al., 2013b; Liang and Marche, 2009). A robust approach designed by Hou et al. (2013a) is utilized, preserving nonnegative water depth in data reconstruction and transforming the slope source term into fluxes so that the whole scheme satisfies the C-property and can deal with the wet-dry interfaces properly. Given that neighboring grids might possess different values of $g^{\prime}$, a centered method, i.e., the FORCE scheme, is utilized to calculate the inter-cell fluxes (Toro, 2009). The corresponding numerical stability is controlled by a decreasing function of the dimension parameter $\alpha$ (Qian et al., 2017; Toro, 2009)

$$
\begin{aligned}
& \Delta t=C r \cdot \max \left(\frac{\left|u_{i, j}\right|+\sqrt{g h_{i, j}}}{\Delta x}, \frac{\left|v_{i, j}\right|+\sqrt{g h_{i, j}}}{\Delta y}\right)^{-1} \\
& 0<C r \leq \sqrt{2 \alpha-1} / \alpha
\end{aligned}
$$

where $\mathrm{Cr}$ represents the Courant number. For present 2D modeling, there is $\alpha=2$. A value of $C r=0.5$ is adopted throughout the paper.

\section{RESULTS AND DISCUSSION}

Four flood events are employed to compare the aforementioned models. To quantify the differences between solutions, the dimensionless discrepancy is defined with the $L^{1}$-norm

$$
L^{1}=\frac{\sum\left|h_{O B J}-h_{R E F}\right|}{\sum h_{R E F}}
$$

where the subscript $R E F$ denotes results chosen as the reference; and the subscript $O B J$ denotes results to be compared.

\section{Idealized dam-break flow on a steep slope}

Fernandez-Feria (2006) provided analytical solutions for frictionless dam-break flows upon non-horizontal beds. Here the methodology introduced in Fernandez-Feria (2006) has been adopted to derive analytical solutions for case with a bed inclining angle of $30^{\circ}$. Following Fernandez-Feria (2006), the results are given in local coordinates and are expressed in terms of dimensionless variables, with the initial water depth $H_{0}$ at the dam wall and $\sqrt{g H_{0}}$ as the length scale and the velocity scale, respectively. The dimensionless spatial step is set to $\Delta x=0.01$, satisfying the criteria of mesh independence.

Figure 2 shows the analytical and the numerical solutions for the advancing flow fronts with time. Apparently, the results calculated by the traditional SVE model deviate greatly from the analytical solutions while those computed by the other two models match rather well with the analytical solutions. Figure 3 illustrates the flow depth and the velocity profiles at four instants of time. The SWE and the CAR predictions agree well with the analytical solutions. However, the SVE model overestimates the flow velocity, demonstrating that the SVE model does not apply to cases with steep slopes.

\section{Experimental dam-break flow in cascade reservoirs with steep slope}

The experiment was carried out at State Key Laboratory of Hydraulic and Mountain River Engineering of Sichuan University (Xue et al., 2011). As shown in Figure 4, ten probes were placed along the bottom to record the flow depth. Two flat plates were vertically set as dams in the flume. Once the force acting on the plate exceeded the ultimate bearing capacity equaling to the hydrostatic pressure in the water depth of 0.53 $\mathrm{m}$., the plate would fall down in less than $0.35 \mathrm{~s}$, simulating an instantly filled dam break. Initial water depths of reservoirs were 


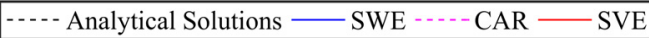
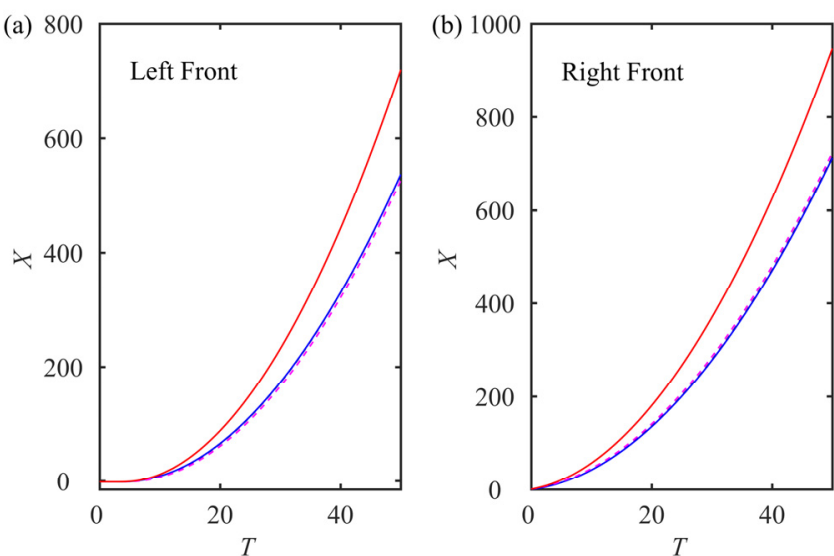

Fig. 2. Analytical and numerical solutions of the locations of the advancing flow fronts with time: (a) left front; (b) right front.

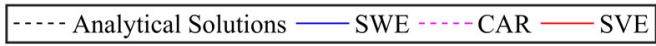
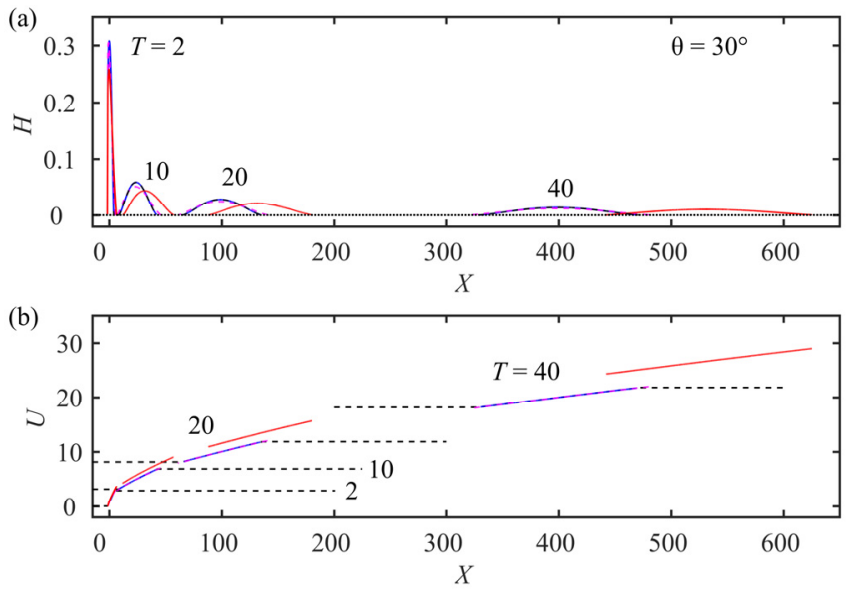

Fig. 3. Analytical and numerical solutions of the flow at four instants of time: (a) depth profiles; and (b) velocity profiles. The black dash lines in (b) are plotted outside the flow region to delineate more clearly the analytical solutions obtained for the velocity of the flow fronts.

$0.494 \mathrm{~m}$ and $0.496 \mathrm{~m}$ for the upstream and the downstream dams, respectively. In line with the mesh independence analysis, a mesh of $\Delta x=0.005 \mathrm{~m}$ is adopted here.
Table 1. Calibrated values of Manning roughness for two models.

\begin{tabular}{|c|c|c|}
\hline Model & Manning Roughness $n$ & Dam-break time (s) \\
\hline \multirow{3}{*}{ SVE } & 0.0170 & 2.38 \\
\cline { 2 - 3 } & $\mathbf{0 . 0 1 7 7}$ & $\mathbf{2 . 4 0}$ \\
\cline { 2 - 3 } & 0.0180 & 2.41 \\
\hline \multirow{3}{*}{ CAR } & 0.0150 & 2.38 \\
\cline { 2 - 3 } & $\mathbf{0 . 0 1 5 5}$ & $\mathbf{2 . 4 0}$ \\
\cline { 2 - 3 } & 0.0160 & 2.41 \\
\hline
\end{tabular}

According to Xue et al. (2011), the downstream dam broke due to the overloading, $2.4 \mathrm{~s}$ after the collapse of the upstream dam. This is used to calibrate the Manning roughness for the SVE and the CAR models, with the aforementioned capacity being the criterion of dam break. The calibration results are listed in Table 1, with values of 0.0177 and 0.0155 for the SVE and the CAR models respectively. This is in accordance with the fact that the traditional SVE model neglects the effects of bed slope so that a larger value of Manning roughness is demanded to prevent the flood from propagating too fast, as compared to the CAR model.

Figure 5 shows the computed depth hydrographs by the CAR and the SVE models at ten gauging points as compared against the measured data (Xue et al., 2011). Although different values of Manning roughness have been adopted in the two models, the results are qualitatively and quantitatively similar, both reproducing the measured data satisfactorily. Given the short duration of about $6 \mathrm{~s}$, the difference between the two models is minor and can only be manifested by the calibrated Manning roughness even though the bottom slope is $12^{\circ}$.

\section{Presumed glacier-lake outburst flooding}

A sudden outburst of a glacier-lake in Pengqu Basin, Tibet, China has been presumed for numerical studies in several previous works (Cao et al., 2007; Wang et al., 2010; Yue et al., 2008). The topography provided in DEM is shown in Figure 6a, with the initial condition the same as that in Wang et al. (2010). The Manning roughness of the whole domain is set to $n=0.05$. The hydrographs of flow depth of four points have been recorded, located at P1 (15561 m, $5928 \mathrm{~m})$, P2 (13053 m, $6954 \mathrm{~m})$, P3 (10659 m, $8550 \mathrm{~m})$, and P4 (5472 m, $18240 \mathrm{~m})$.

Figure 6 illustrates the evolution of the free surface of the GLOF simulated by the CAR model, which is qualitatively similar to that of Wang et al. (2010). Figure 7 shows the depth hydrographs of four selected points. Note that P1 and P2 are located within the glacial-lake. The fictitious vibration of flow depth in Figure $7 \mathrm{~b}$ dictates that the model employed by Wang et

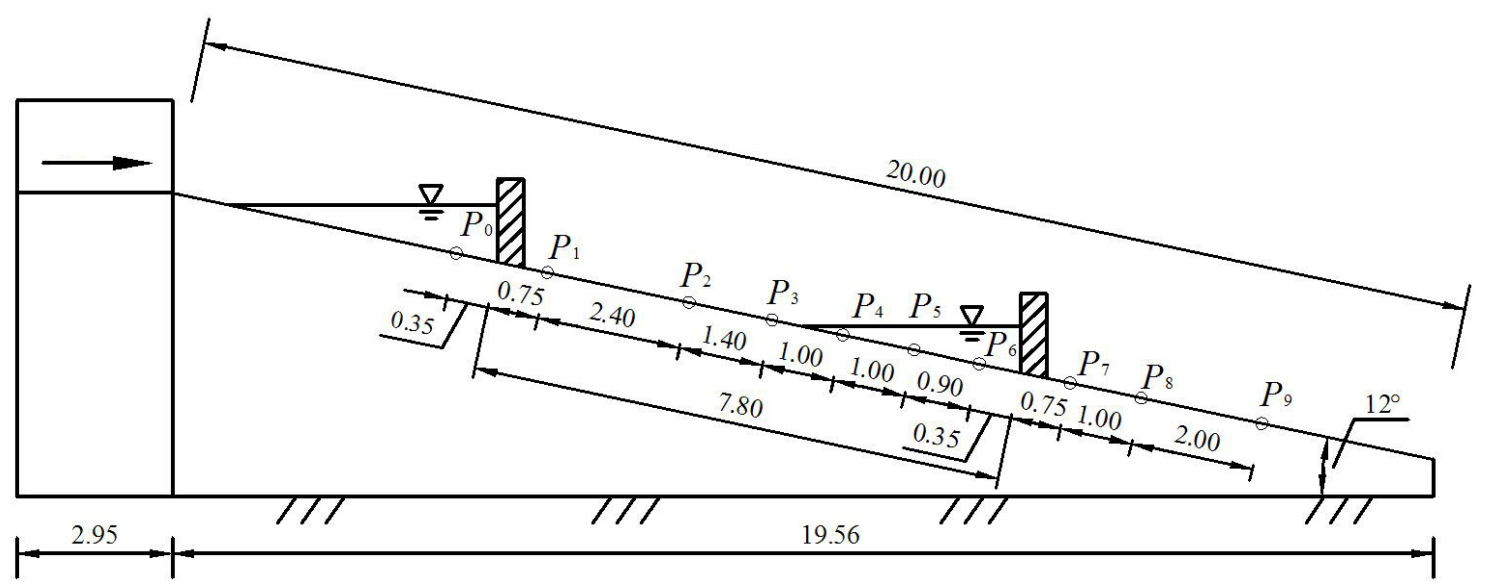

Fig. 4. Sketch of the flume and the layout of gauging points (unit: m). 

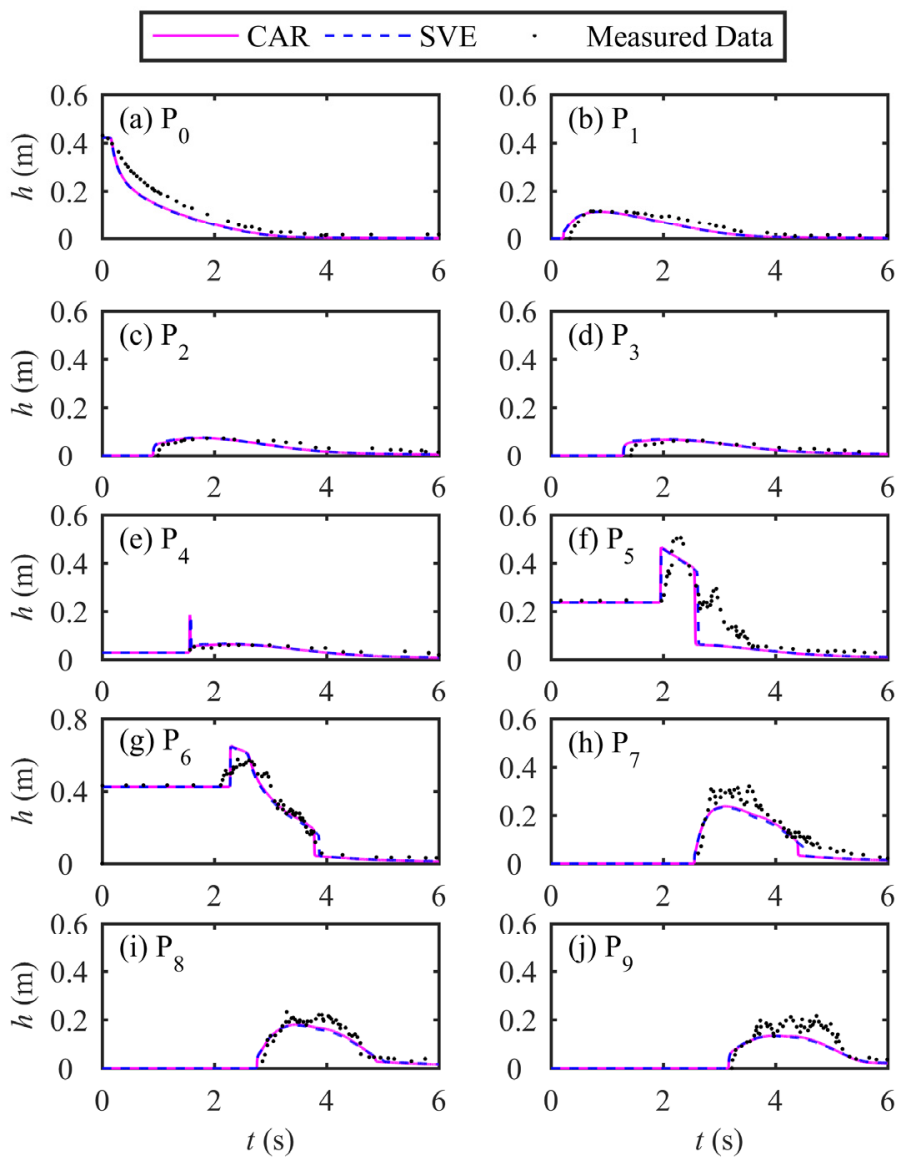

Fig. 5. Computed depth hydrographs compared against measured data.
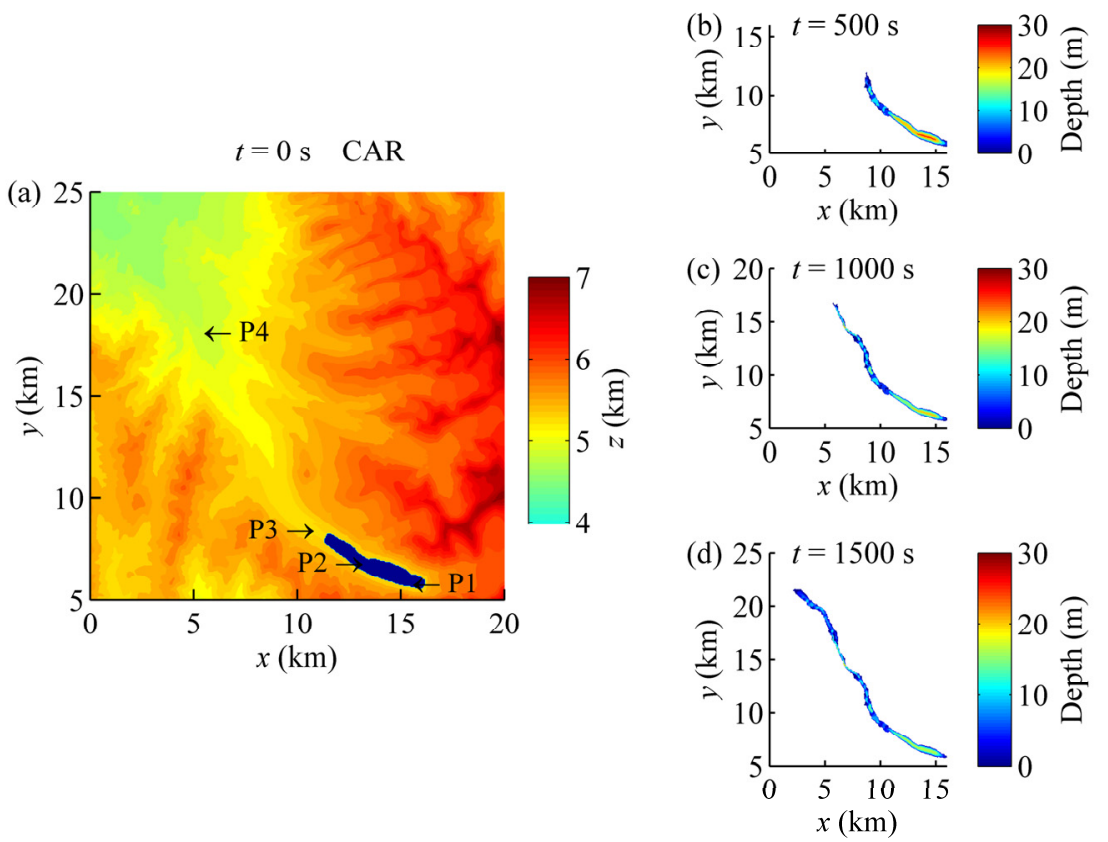

Fig. 6. Top view: (a) the study area and the initial state of the glacier-lake; and (b)-(d) distributions of flow depth.

al. (2010) was not well-balanced. On the contrary, the results given by the CAR and the SVE models feature a period of static state for both P1 and P2, demonstrating the enhanced performance of the numerical models used in the present work. On the other hand, the curves given by the two models are almost indistinguishable in Figure 7. Table 2 presents the quantitative differences between those two results and both the $L^{1}$-norm and the relative error of arriving time at Point $\mathrm{P} 4$ are larger than those at Point P3, in line with the fact that $\mathrm{P} 4$ is downstream of $\mathrm{P} 3$.

Although the simulation has been carried out for $25 \mathrm{~min}$, the discrimination between the two models remains minor. This is because the average slope of the main channel is $8.3 \%$ (Wang et al., 2010), still within the range of small slope. Hence, the SVE model holds its validity in application to cases with small slopes. 

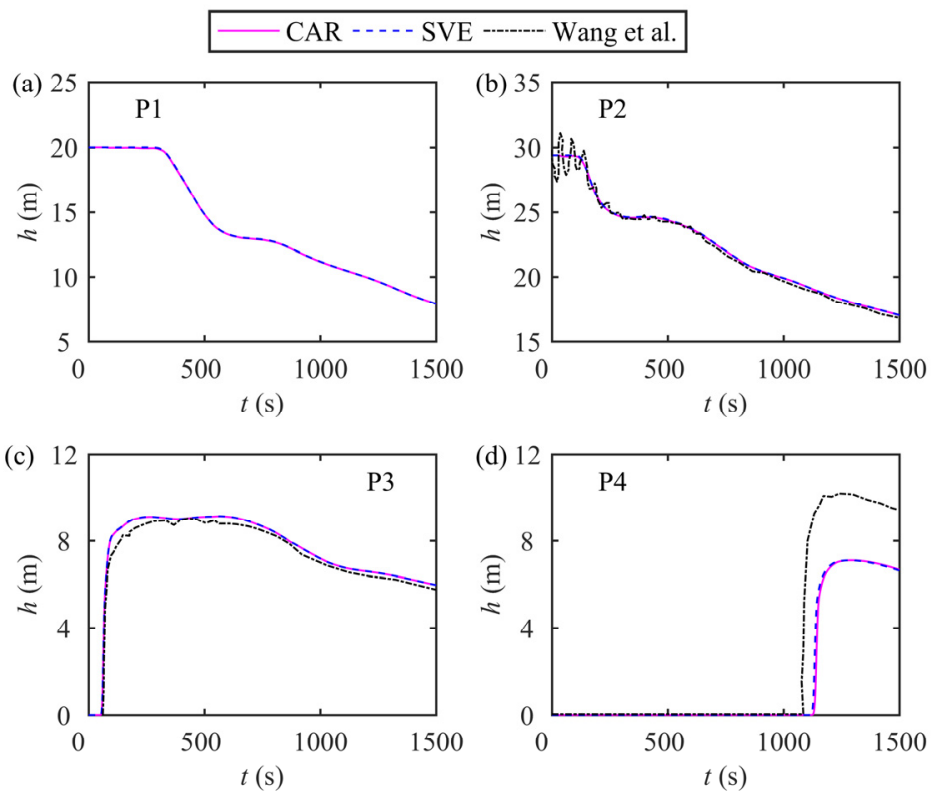

Fig. 7. Hydrographs of flow depth at P1-P4.

Table 2. Comparison of the results calculated by two models at Points P3 and P4.

\begin{tabular}{|l|c|c|c|c|}
\hline Point & Model & $L^{1}(\%)$ & $\begin{array}{c}\text { Arriving time } \\
(\mathrm{s})\end{array}$ & $\begin{array}{c}\text { Relative error } \\
(\%)\end{array}$ \\
\hline \multirow{2}{*}{ P3 } & SVE & $/$ & 44.71 & $/$ \\
\cline { 2 - 5 } & CAR & 0.08 & 44.78 & 0.15 \\
\hline \multirow{2}{*}{ P4 } & SVE & $/$ & 1100.58 & $/$ \\
\cline { 2 - 5 } & CAR & 2.31 & 1108.09 & 0.68 \\
\hline
\end{tabular}

\section{Hypothetical dam-break flood induced by the sudden release of a barrier lake}

Since the SVE and the CAR models exhibit minor difference in flood events with short duration or small bed slope, a relatively large-scaled catchment is designated here, covering an area of $10 \mathrm{~km} \times 8 \mathrm{~km}$. A barrier lake with a volume of more than $160000 \mathrm{~m}^{3}$, is presumed to collapse completely. The maximum water depth before the dam is $20 \mathrm{~m}$. The average channel slope along the thalweg is approximately $21.9 \%$, with the piecewise linear expression given below

$$
e= \begin{cases}0.00 & \text { if } x \leq 0 \mathrm{~km} \\ 0.60 & \text { if } x \leq 0.4 \mathrm{~km} \\ 0.54 & \text { if } x \leq 0.9 \mathrm{k} \mathrm{m} \\ 0.36 & \text { if } x \leq 1.9 \mathrm{k} \mathrm{m} \\ 0.24 & \text { if } x \leq 4.9 \mathrm{k} \mathrm{m} \\ 0.12 & \text { if } x>4.9 \mathrm{k} \mathrm{m}\end{cases}
$$

The lateral cross sections are designed to be parabolic and symmetric for simplicity, with eight points $\mathrm{P} 1-\mathrm{P} 8$ selected along the thalweg, which are located at $0.2 \mathrm{~km}, 1.4 \mathrm{~km}, 2.6 \mathrm{~km}$, $3.8 \mathrm{~km}, 5.0 \mathrm{~km}, 6.2 \mathrm{~km}, 7.4 \mathrm{~km}$, and $8.6 \mathrm{~km}$ downstream of the dam (Figure 8). The Manning roughness is supposed to be $n=0.025$ throughout the whole region. The spatial steps are $\Delta x=\Delta y=20 \mathrm{~m}$.

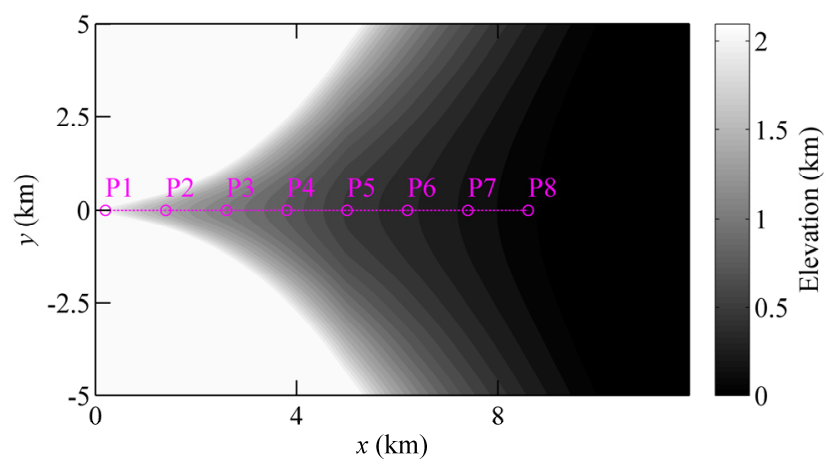

Fig. 8. Top view of the study area.

Figure 9 illustrates the distributions of flow depth at four instants of time. The flood computed by the CAR model propagates slower than that simulated by the SVE model. Correspondingly, the flow depth from the CAR modeling is deeper than that predicted by the SVE model at the same location.

A set of increased Manning roughness has been chosen for the SVE model to test if an increased drag force, which can slow down the propagation of flood, would make up for the neglect of bed slope effects in the SVE model. The arriving times computed by the SVE model with $n=0.025$ are set as references, and those calculated by the SVE models with tuned Manning roughness and the CAR model minus the references are the lag times. Figure 10 illustrates that an increased roughness coefficient adopted by the SVE model does slow down the propagation of flood, but the corresponding upward concave curves deviate remarkably from that of the CAR model, which features a downward concavity. Essentially, the influence of an increased drag force accumulates downstream while the discrepancy of the CAR and the SVE model is in line with the bed slope. Since an increased drag force cannot compromise the neglect of bed slope effects in the SVE model, the CAR model is recommended for flood events, especially those featuring both long durations and steep bed slopes. 

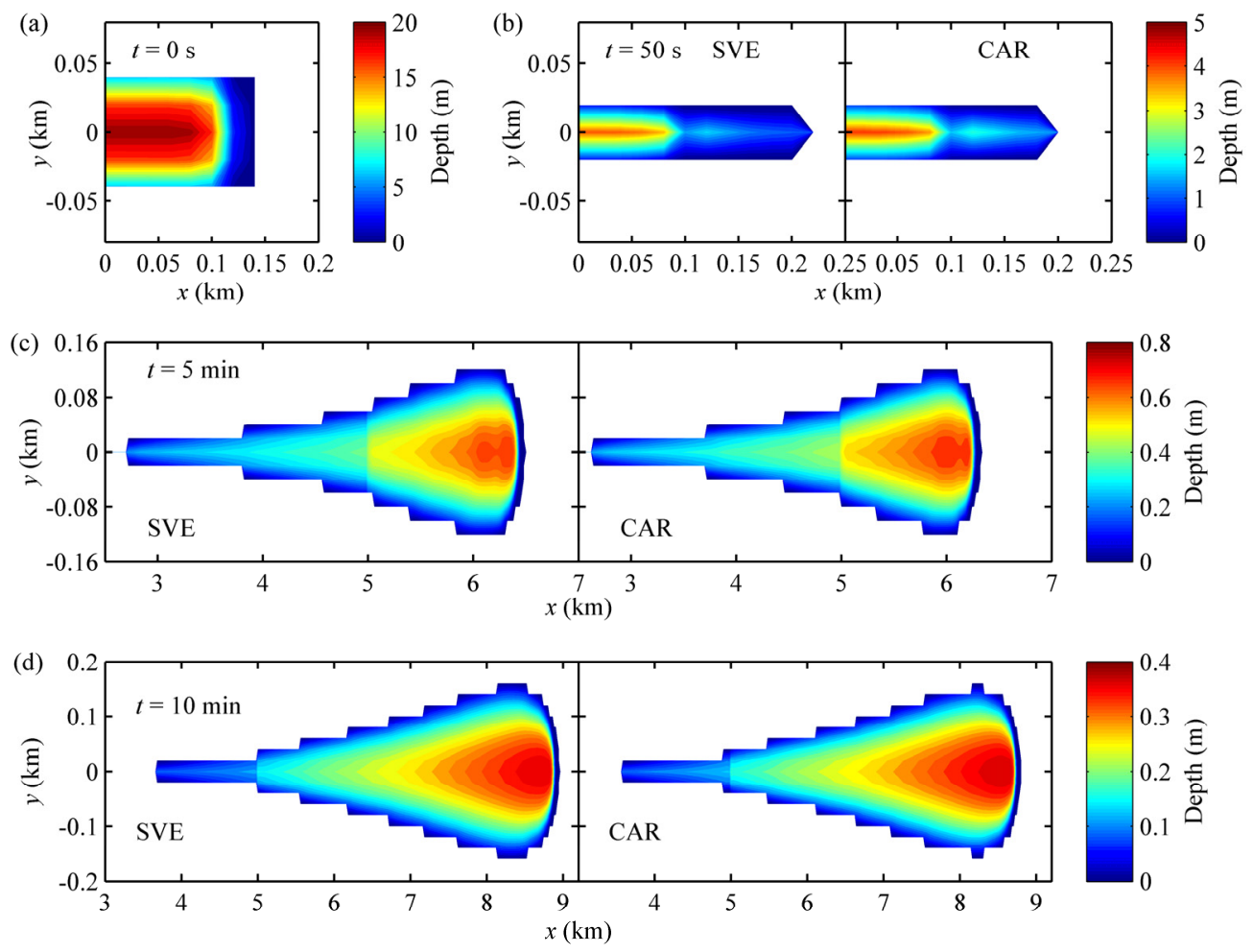

Fig. 9. Distributions of flow depth at four instants of time.

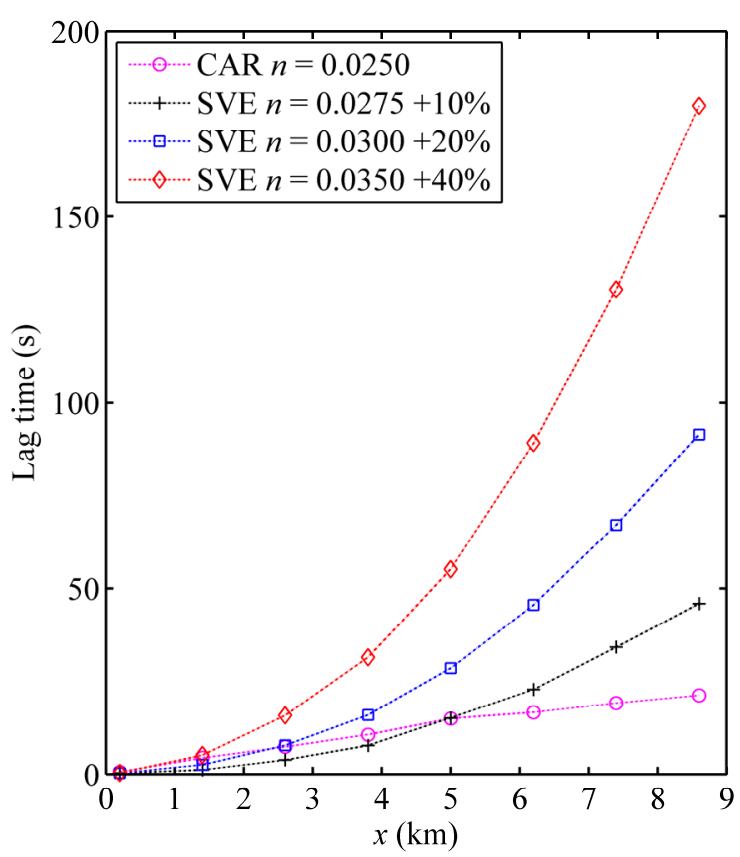

Fig. 10. Lag times of flood arriving at eight points predicted by different model or values of Manning roughness. The results computed by SVE model with the Manning roughness set to 0.025 are chosen as references.

\section{CONCLUSIONS}

A 2D hydrodynamic (labeled as CAR) model has been proposed for shallow water flows over steep slopes in a Cartesian coordinate system with two axes within the horizontal plane and one axis along the vertical direction, taking into account the bed slope when calculating pressure distribution and bed shear stresses. A well-balanced finite volume method, which achieves second-order accuracy in time and space, has been adopted to solve the governing equations.

The CAR model is tested against the analytical solutions of an idealized dam-break flow over a steep slope, along with the traditional SVE model and the modified SWE model. Both the CAR and the SWE models satisfactorily reproduce the analytical solutions, while the SVE model overestimates the flow velocity so it does not apply to cases with steep slopes. Although the CAR and the SVE models give results with minor differences for cases with short duration or small mean slope, the SVE model keeps predicting a faster propagation of flood. In this connection, a flood event has been designed with longer duration and larger average slope, and the two models present distinguishable discrepancies. Extensively, an increased drag force cannot compromise the neglect of bed slope effects in the SVE model. Hence, the proposed CAR model is advocated for applications for its facility of extending from 1D to $2 \mathrm{D}$ version and simple data handling as opposed to the SWE model.

Extensions of the present work can focus on the fully coupled shallow water hydro-sediment-morphodynamic models incorporating rainfall and infiltration and their practical applications, such as rainfall-induced flash floods in watersheds.

Acknowledgements. The work reported in this paper is funded by the Natural Science Foundation of China (Grant Nos. 11432015 and 51279144).

\section{REFERENCES}

Ancey, C., Iverson, R.M., Rentschler, M., Denlinger, R.P., 2008. An exact solution for ideal dam-break floods on steep slopes. Water Resour. Res., 44, 1, W01430.

Barré de Saint-Venant, A.J.C., 1871. Théorie du mouvement non permanent des eaux, avec application aux crues des rivières et à l'introduction des marées dans leur lits. Comptes 
Rendus des séances de l'Académie des Sciences, 73, 1871, 237-240. (In French.)

Bouchut, F., Mangeney-Castelnau, A., Perthame, B., Vilotte, J., 2003. A new model of Saint Venant and Savage-Hutter type for gravity driven shallow water flows. C. R. Acad. Sci. Paris, 336, 6, 531-536.

Bussing, T.R.A., Murmant, E.M., 1988. Finite-volume method for the calculation of compressible chemically reacting flows. AIAA J., 26, 9, 1070-1078.

Cantero-Chinchilla, F.N., Castro-Orgaz, O., Khan, A.A., 2017. Depth-integrated non-hydrostatic free-surface flow modelling using weighted-averaged equations. Int. J. Numer. Mech. Fluids, 87, 1. DOI: 10.1002/fld.4481.

Cao, Z.X, Yue, Z., Li, X., Che, T., 2007. Two-dimensional mathematical modeling of flooding over erodible sediment bed. Proceedings of the 32nd IAHR Congress, Venice, Italy. CD-ROM, IAHR, Madrid.

Cao, Z.X, Hu, P., Hu, K., Pender G., Liu, Q.Q., 2015. Modelling roll waves with shallow water equations and turbulent closure. J. Hydraul. Res., 53, 2, 161-177.

Cao, Z.X, Xia, C.C., Pender, G., Liu, Q.Q., 2017. Shallow water hydro-sediment-morphodynamics equations for fluvial processes. J. Hydraul. Eng., 143, 5, 02517001.

Castro-Orgaz, O., Hager, W.H., 2017. Non-Hydrostatic Free Surface Flows. Springer International Publishing AG, Cham, Switzerland.

Castro-Orgaz, O., Hutter, K., Giraldez, J.V., Hager, W.H., 2015. Nonhydrostatic granular flow over 3-D terrain: New Boussinesq-type gravity waves? J. Geophys. Res., 120, 128.

Denlinger, R.P., Iverson, R.M., 2004. Granular avalanches across irregular three-dimensional terrain: I. Theory and computation. J. Geophys. Res., 109, F01014.

Denlinger, R.P., O'Connell, D.R.H., 2008. Computing nonhydrostatic shallow-water flow over steep terrain. J. Hydraul. Eng., 134, 11, 1590-1602.

Fernandez-Feria, R., 2006. Dam-break flow for arbitrary slopes of the bottom. J. Eng. Math., 54, 4, 319-331.

Gray, J.M.N.T., Wieland, M., Hutter, K., 1999. Gravity-driven free surface flow of granular avalanches over complex basal topography. Proc. R. Soc. Lond. A, 455, 1841-1874.

Greve, R., Koch, T., Hutter, K., 1994. Unconfined flow of granular avalanches along a partly curved surface. I. Theory. Proc. R. Soc. Lond. A, 445, 399-413.

Hou, J., Liang, Q., Simons, F., Hinkelmann, R., 2013a. A 2D well-balanced shallow flow model for unstructured grids with novel slope source term treatment. A $\overline{d v}$. Water Resour., 52, 107-131.

Hou, J., Liang, Q., Simons, F., Hinkelmann, R., 2013b. A stable 2D unstructured shallow flow model for simulations of wetting and drying over rough terrains. Comput. Fluids, 82, 132-147.

Huang, W., Cao, Z.X, Carling, P., Pender, G., 2014. Coupled $2 \mathrm{D}$ hydrodynamic and sediment transport modeling of megaflood due to glacier dam-break in Altai Mountain, Southern Siberia. J. Mt. Sci., 11, 6, 1442-1453.

Huang, W., Cao, Z.X, Qi, W., Pender, G., Zhao, K., 2015. Full 2D hydrodynamic modelling of rainfall-induced flash floods. J. Mt. Sci., 12, 5, 1203-1218.

Juez, C., Murillo, J., García-Navarro, P., 2013. 2D simulation of granular flow over irregular steep slopes using global and local coordinates. J. Comput. Phys., 255, 166-204.
Juez, C., Soares-Frazao, S., Murillo, J., García-Navarro, P., 2017. Experimental and numerical simulation of bed load transport over steep slopes. J. Hydraul. Res., 55, 4, 455-469.

Keller, J.B., 2003. Shallow-water theory for arbitrary slopes of the bottom. J. Fluid Mech., 489, 345-348.

Li, J., Cao, Z.X., Qian, H.L., Liu, Q.Q., Pender, G., 2017. A depth-averaged two-phase model for fluvial sediment-laden flows over erodible beds. Adv. Water Resour., in press. https://doi.org/10.1016/j.advwatres.2017.08.014

Li, J., Cao, Z.X, Hu, K., Pender, G., Liu, Q.Q., 2018a. A depthaveraged two-phase model for debris flows over fixed beds. Int. J. Sediment Res., 33, 4, 462-477.

Li, J., Cao, Z.X, Hu, K., Pender, G., Liu, Q.Q., 2018b. A depthaveraged two-phase model for debris flows over erodible beds. Earth Surf. Process. Landforms, 43, 817-839.

Liang, Q., Marche, F., 2009. Numerical resolution of wellbalanced shallow water equations with complex source terms. Adv. Water Resour., 32, 873-884.

Mangeney-Castelnau, A., Bouchut, F., Vilotte, J. P., Lajeunesse, E., Aubertin, A., Pirulli, M., 2005. On the use of Saint Venant equations to simulate the spreading of a granular mass. J. Geophys. Res., 110, B09103.

Qian, H.L., Cao, Z.X, Pender, G., Liu, H.H., Hu, P., 2015. Well-balanced numerical modelling of non-uniform sediment transport in alluvial rivers. Int. J. Sediment Res., 30, 2, 117-130.

Qian, H.L., Cao, Z.X, Liu, H.H., Pender, G., 2017. Numerical modeling of alternate bar formation, development and sediment sorting in straight channels. Earth Surf. Process. Landforms, 42, 4, 555-574.

Savage, S.B., Hutter, K., 1989. The motion of a finite mass of granular material down a rough incline. J. Fluid Mech., 199, $177-215$.

Savage, S.B., Hutter, K., 1991. The dynamics of avalanches of granular materials from initiation to runout. Part I : Analysis. Acta Mechanica, 86, 1, 201-223.

Toro, E.., 2001. Shock-Capturing Methods for Free-Surface Shallow Flows. Chichester, U. K.: Wiley.

Toro, E.F., 2009. Riemann Solvers and Numerical Methods for Fluid Dynamics: A Practical Introduction. $3^{\text {rd }}$ Ed. SpringerVerlag, Berlin.

Van Emelen, S., 2014. Breaching processes of river dikes: effects on sediment transport and bed morphology, (Doctoral dissertation). Retrieved from DIAL. (http://hdl/handle.net/2078.1/151925). Université catholique de Louvain, Leuven, Belgium.

Van Emelen, S., Zech, Y., Soares-Frazao, S., 2014. Limitations of the shallow water assumptions for problems involving steep slopes: Application to a dike overtopping test case. In: River Flow 2014, Lausanne, pp. 1669-1677.

Wang, X., Cao, Z.X, Pender, G., Neelz, S., 2010. Numerical modeling of flood flows over irregular topography. Proc. ICE - Water Manage., 163, WM5, 255-265.

Wu, W., 2007. Computational River Dynamics. Taylor \& Francis, London, UK.

Xue, Y., Xu, W., Luo, S., Chen, H., Li, N., 2011. Experimental study of dam-break flow in cascade reservoirs with steep bottom slope. J. Hydrod. B, 23, 4, 491-497.

Yue, Z., Cao, Z., Li, X., Tao, C., 2008. Two-dimensional coupled mathematical modeling of fluvial processes with intense sediment transport and rapid bed evolution. Sci. China Ser. G-Phys. Mech. Astron., 51, 9, 1427-1438. 